\title{
Building our presence on campus The University Libraries Section's (ULS) groups address advocacy and leadership issues at the ALA Midwinter Meeting
}

O ne of the most interesting aspects of modern academic librarianship is the constantly evolving and, many would argue, expanding, role that libraries play on our university campuses. The academic library has traditionally been regarded as a place of research, study, and quiet re ection; and to some extent, libraries still can, and do, serve these functions. However, through the creative application of new computer and communication technologies, university libraries have begun to position themselves in a manner that is more central to the educational and intellectual goals of our institutions. This is evidenced by the expansion of library-based instruction and outreach programs, by the repurposing of physical space to allow for the housing of digital learning commons areas, by the leadership positions librarians have accepted in arenas such as the development of institutional repositories and the evolution of intellectual property rights, and so on.

The result of this repositioning is that today s academic library is viewed not merely as a physical space in which to warehouse items, but a central location from which the delivery of various forms of informational content can be directed in an effort to enhance the educational missions of the university. It is with this repositioning in mind that ULS appears to be focusing a large amount of its efforts on developing conference programs, workshops, and discussion group topics.

In looking at activities and programs sponsored by various ULS groups in 2007 at the ALA Midwinter Meeting and Annual Conference and the ACRL National Conference, a pattern of supporting the expanded focus of librarianship emerges, especially in the areas of promoting campus advocacy and leadership at all levels within the library. This report includes summaries of the activities at the ALA Midwinter Meeting of two of the ULS groups that are focusing on these topics, as well as additional information regarding upcoming ULS events and workshops.

\section{ULS Executive Committee}

It is widely recognized that a majority of the leadership positions in academic libraries are currently held by members of the baby boom generation. With the expectation of a mass retirement of these individuals occurring over the next decade, there exists a real concern about how our nation s libraries will respond to such a large amount turnover in upper administration. In recognition of this issue, the ULS Executive Committee reported at its Midwinter meeting that the section will be sponsoring a program at the ALA Annual Conference in Washington, D.C., June 21 27, 2007, entitled Leadership or Management: Which Is It?

The focus of this session will be on what libraries can do to address the impending retirement of a generation of library leaders. The typical program agenda of keynotespeaker-followed-by-panel-reaction will be reversed for this session. The members of the panel will speak rst, followed by a reaction from the keynote speaker. During the twohour session, the presenters will rst establish what de nes good leadership and effective management, and go on to explore various

J. Michael Thompson is head of acquisitions at the University of Houston, e-mail: jmthompson@uh.edu

๑ 2007 J. Michael Thompson 
methods and means of developing future managers and leaders. During the program, the speakers will be addressing how leadership can be developed at all levels of an organization. As such, librarians at all career stages are being encouraged to attend.

The panel will consist of Karen Williams (associate university librarian at the University of Minnesota) and Sheldon McCorn (head of access services at the University of California-Los Angeles). The keynote reaction will be given by Julie Todaro (dean of library Services at Austin Community College and ACRL vice president). The program is scheduled for Saturday, June 23, from 1:30 to $3: 30$ p.m. The annual ULS Social will be held immediately following the program.

The Executive Committee also reviewed its plans for a workshop on advocacy that was held during the ACRL National Conference in Baltimore. Entitled Campus Advocacy: Involving All Staff in In uencing Campus Dynamics, the free workshop addressed the importance of involving all library staff in campus advocacy programs. With a group of speakers from a range of backgrounds, one goal of this session was to explore the bene ts that can be achieved when a more holistic approach to advocacy is employed. During the session, the participants also reviewed different ways in which library staff at all levels can assist with efforts to promote library initiatives more effectively on campus.

The members of the Executive Committee have realized that there is an inherent complication with producing a workshop for a national conference that is designed to promote the involvement of all levels of library staff: not everyone, particularly nonprofessional staff and students, have the time, money, and inclination to attend a national library conference. As a result, the committee is attempting to use this initial workshop as a model for future workshops that could be offered at the local level through the various ACRL chapters. The results of such an initiative would be exciting if it could be effectively implemented to reach the various members of the library community who are unable to participate at the national level.

For individuals who missed the workshop at the ACRL National Conference but will be attending ALA Annual in Washington, D.C., there will be an Advocacy Institute held on Friday, June 22, from 8:30 a.m. to 3:30 p.m.. The price of advanced registration is $\$ 35$ and on site registration is $\$ 50$. This institute is not a part of the ULS workshop discussed above nor is it being sponsored by the ULS itself, but it does offer another chance to learn about advocacy. Additional information regarding this institute can be found under the Issues \& Advocacy tab on the ALA homepage.

\section{Campus administration and leadership discussion group}

Discussion group convener David Gleim (dean/director of the Auraria Library in Denver, Colorado) runs a strictly classic style of discussion group meeting: a topic is announced and individuals who want to discuss that topic show up at the appointed meeting time to discuss it. There are no designated presenters, facilitation exercise leaders, or PowerPoint presentations. The meetings consist solely of a discussion of the topic by those in the group. I found this approach quite refreshing. And judging by the attendance and level of participation that was exhibited at the group s Midwinter meeting, I was not alone.

The session, entitled What Do You Do When ?, was a discussion of the various successes and failures that attendees had encountered when trying to approach university administrators with library initiatives, especially in cases where the administrators were neither aware of the importance of an initiative nor the basic issues surrounding it. The discussion moved along quickly. One meeting participant would put forth a situation he or she had encountered, and others would respond with solutions and ideas for addressing it.

As might be expected, one of the major topics of the discussion was the need to build stronger relationships with those across 
campus. Group members stressed the need to get out of the library building itself. Librarians were encouraged to interact regularly with others in the university community as a means of fostering more effective lines of communication regarding library issues and concerns. Members also encouraged others to seek out and take advantage of any opportunity to talk with university administrators.

A few of the suggestions for building better relationships on campus were:

joining university committees to ensure the library s perspective is represented; using direct involvement with campus celebrations and activities (e.g., anniversaries, homecoming, etc.) to market library resources and services;

partnering with other groups on campus to help address larger (and often nontraditional) issues, such as preventing plagiarism or developing an institutional repository; and

maintaining previously established relationships both as a means of keeping the library in people s minds and as a way of learning more about opportunities and changes occurring around campus.

Another item stressed during the discussion was that communication with university administrators is far less effective if not presented in a manner that they understand and that ts with their concerns. Discussion group members pointed out several times that librarians should be able to show how each proposed library initiative will bene $t$ the campus before bringing those initiatives before the administration. Librarians will want administrators to see easily how the outcome of a project ts into the mission and goals of the university as a whole. This was deemed especially important when dealing with more esoteric topics (e.g., federated searching), where the bene ts of the initiative may not be immediately apparent to an individual outside of the library community.

It was also mentioned that periods of administrative transitions can provide great opportunities for library advocacy. Transition periods often provide both potential forums to revisit how the library serves the campus and chances to bring library issues to new, and potentially receptive, individuals.

Focusing on outcome-based communication is also important when talking with faculty. If the faculty can see how a library project can help them, the library stands a better chance of getting additional faculty back up for proposals. All discussion group members appeared to agree that taking the time to speak to faculty in ways that show how the library can address their concerns is a great rst step to gaining their understanding and eventual support.

For initiatives that the library feels are not being given the proper level of support at the university level, one meeting attendee suggested that the library consider setting up a smaller pilot program. The idea is that once a successful pilot has been established, it should be easier to demonstrate the results that can be achieved by the initiative and how a larger version of the project would be implemented. The pilot can provide a concrete example that the library can use as a discussion point when trying to advocate for the larger, more far-reaching program.

One of the last issues discussed was the use of a library s student workers as a means of gathering and disseminating information. It was suggested that this group represents a generally underutilized base of communication and support for library causes. The student workers are a particularly useful resource because they nd themselves in both camps. They are, at once, internal and external to the library. They are likely to have rsthand knowledge of the concerns and needs of their fellow students. They also are likely to have a fairly good understanding of the basic operation and function of the library. Discussion group attendees put forth that the knowledge and ideas of student workers might be elicited by forming a student-library advisory committee or by holding regular student worker-based focus groups.

Overall, this hour-long discussion covered many interesting ideas and practical suggestions for working with others on campus to help achieve library initiatives. For individuals 
interested in attending this group s meeting at the ALA Annual Conference, the meeting is scheduled for Saturday, June 23, from 10:30 to 11:30 a.m. The proposed topic is a review/discussion of the management-related presentations and workshops from the ACRL National Conference, including but not limited to the following:

Campus Advocacy: Involving All Staff in In uencing Campus Dynamics

Perceptions of Campus-Level Advocacy and In uence Strategies among Senior Administrators, and

Inside the Academic Administrator $\mathrm{s}$ Mind.

It is hoped that individuals who were able go to these sessions will come to the meeting, provide a brief summary, and then initiate the discussion. The discussion group convener, David Gleim, is encouraging the attendance of those who missed the ACRL National Conference, too. The discussion will be opened up to the entire group after each brief summary is given.
Given the new outwardly focused stance toward which many academic libraries are moving, it is good to see that ULS is making a concerted effort to support its members through various workshops, presentations, and discussion groups focusing on administrative issues, such as campus advocacy and leadership. These ULS sessions appear to cover the relevant material well and deliver very practical information and suggestions that can be applied when the librarians return home after the conference. In the near future, it will be especially interesting to see the impact that conducting advocacy workshops at the local level will have on getting all members of a librarys staff to advocate for the librarys agenda.

I would de nitely encourage those interested in the issues surrounding library advocacy and leadership to make efforts to attend and participate in the upcoming ULS events reported above, as well as any of the other ULS sessions at the ALA Annual Conference this summer. 2

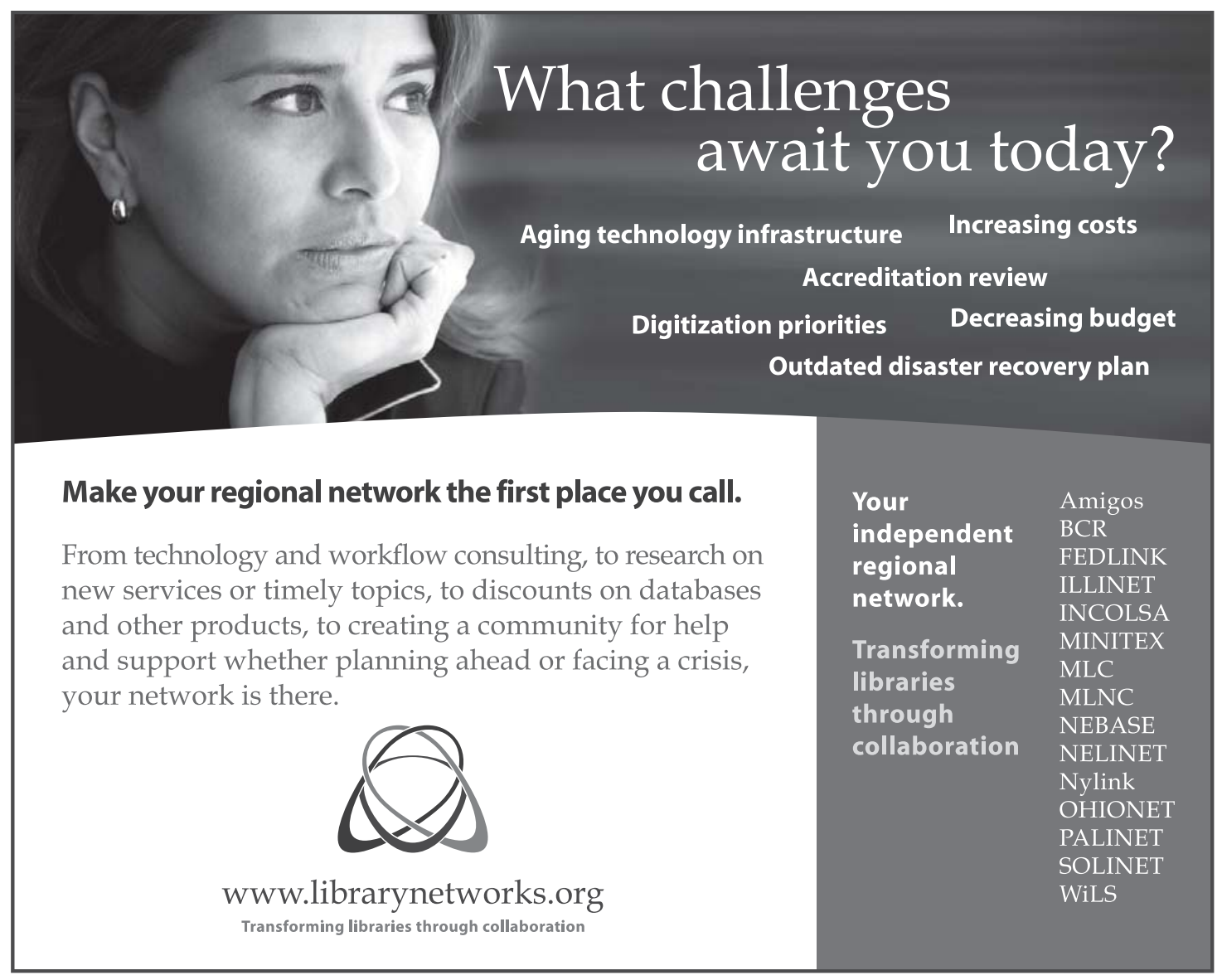

